\title{
Broad-band Monolithic GaAs-based HEMT Diode Mixers
}

\author{
K. L. Deng, Y. B. Wu, Y. L Tang, H. Wang, and C. H. Chen \\ Dept. of Electrical Engineering and Graduate Institute of Communication Engineering, \\ National Taiwan University, Taipei, Taiwan, 10617, ROC
}

\begin{abstract}
Broad-band monolithic diode mixers covering $17.5-33 \mathrm{GHz}$ with different topologies are designed, fabricated and tested. The topologies under investigation include the singly balanced mixer with $90^{\circ}$ and $180^{\circ}$ coupler and the sub-harmonically pumped (SHP) mixer. These monolithic microwave integrated circuits are fabricated using a $0.2-\mu \mathrm{m}$ pseudomorphic HEMT foundry process on a 4-mil thick GaAs substrate, and thus the measurement results for each topology are evaluated on a fair basis. The SHP mixer, with a miniature size of $1.3 \mathrm{~mm} \times 1.1 \mathrm{~mm}$, demonstrates $10-12 \mathrm{~dB}$ conversion loss at 17.5-33 GHz of RF with 2.5-GHz IF and both LO-to-RF, LO-to-IF isolations of both better than $25 \mathrm{~dB}$. It outmatches the singly balanced approaches, as well as achieves rival performance compared with previously reported results at similar frequencies.
\end{abstract}

\section{INTRODUCTION}

Future radio communication systems require low-cost and high-performance RF components. In transmit/receive (T/R) modules, the mixers server core functions to convert the high frequency signal to IF signal and vice versa. For a broadband application, balanced diode mixer with a broadband coupler is a typical mixer topology to choose. Another approach is sub-harmonically pumped (SHP) mixer with a pair of anti-parallel diodes [1]. On the other hand, monolithic approach to implement a mixer has a number of advantages over the hybrid one in high volume production. This paper presents three broad-band MMIC diode mixers with different topologies from 17.5 to $33 \mathrm{GHz}$ frequency range, including a singly balanced (SB) mixer with $90^{\circ}$ Lange coupler, another one with $180^{\circ}$ modified rat-race coupler, and a SHP mixer. These mixers are fabricated using a $0.2-\mu \mathrm{m}$ pseudomorphic HEMT foundry process on a 4-mil thick GaAs substrate, and thus the measurement results for each topology are evaluated on a fair basis. All three mixers have been tested for various parameters and evaluated. The SHP mixer, with a miniature size of $1.3 \mathrm{~mm} \times 1.1 \mathrm{~mm}$, demonstrates $10-12 \mathrm{~dB}$ conversion loss at $17.5-33 \mathrm{GHz}$ of RF with $2.5-\mathrm{GHz}$ IF and both LOto-RF, LO-to-IF isolations of both better than $25 \mathrm{~dB}$ and outmatches the singly balanced approaches. The comparison of different diode mixer approaches, together with previously published results, will be also presented in this paper.

\section{CIRCUIT DESIGN}

The MMIC mixers were fabricated using GaAs-based pseudormorphic HEMT (PHEMT) MMIC process foundry service provided by Philips Microwave Limeil, France [2]. The device is a $0.2-\mu \mathrm{m}$ gate-length low noise PHEMT with a unit current gain frequency $\left(f_{T}\right)$ of 53 $\mathrm{GHz}$. The passive components include GaAs bulk resistor, MIM capacitor, and via hole through $100-\mu \mathrm{m}$ GaAs substrate. The entire chip is also protected by silicon-nitride passivation for reliability concern. The mixing diode is simply using the HEMT device with drain and source connected together. All the three mixers utilize a common size of 4-finger $80-\mu \mathrm{m}$ gate width HEMT diode device with a cutoff frequency of $72 \mathrm{GHz}$. The individual mixer designs are described as follows.

SHP Mixer. A SHP mixer using an anti-parallel diodes can reduce the number of multipliers in the LO chain, requires no dc power, can be used for both frequency up and down conversion and reject all even harmonics [1]. Fig. 1(a) shows the circuit diagram of the SHP mixer. The circuit is designed to operate at RF frequencies of $17.5-33 \mathrm{GHz}$ and IF frequencies of 2.5-4 GHz using the second harmonic of the LO input signal. The mixing elements are a 
pair of anti-parallel gate-HEMT Schottky diodes. The mixer uses a high-pass filter for RF range of $15-40 \mathrm{GHz}$ and eliminates unwanted $\mathrm{LO}$ harmonics from reaching the RF input port. Two quasi-lumped quarter-wave short and open stubs are used to provide LO-to-RF isolation and reduce the chip area, as well as increase the bandwidth similar to that reported in [3]. The mixer also uses a low-pass filter in front of the IF port for RF- and LO-to-IF port isolation. The chip photo is shown in Fig. 1(b), with a chip size of $1.3 \mathrm{~mm} \times 1.1 \mathrm{~mm}$.

Singly Balanced Mixers. The advantages and disadvantages of SB mixer are well documented in [1],[5]. Fig. 2(a) shows the circuit diagram of both the singly balanced diode mixer with $180^{\circ}$ and $90^{\circ}$ couplers. The major difference of the mixer using $180^{\circ}$ and $90^{\circ}$ couplers is that the one with $180^{\circ}$ coupler can be used for both frequency up and down conversion, while the one with $90^{\circ}$ coupler only for down conversion [4]. In addition, the one with $180^{\circ}$ coupler has better RF-to-IF isolation but worse return loss while the one with $90^{\circ}$ coupler has the opposite feature [5].

In the SB mixer with $180^{\circ}$ coupler, the modified rat-race coupler is used for the coupler instead of a conventional one for bandwidth concern [1],[6]. The three quarter-wave length 50- $\Omega$ transmission line which serves as a half-wavelength phase inverter in conventional ratrace ring is replaced by a $50-\Omega$ Lange coupler in order to increase the hybrid bandwidth as well as reduce the chip size. A simple T-impedance transformer is used for the diode matching and a low pass filter is lead from the center of the diode pair to IF port.

For the SB mixer with $90^{\circ}$ coupler, the Lange coupler was selected for bandwidth and simplicity. Similar matching technique and low-pass filter are implemented as the previous one. The chip photos for both mixers with $180^{\circ}$ and $90^{\circ}$ couplers are shown in Fig. 2(b) and 2(c). The chip sizes are $2.1 \mathrm{~mm} \times 2 \mathrm{~mm}$ and $1.5 \mathrm{~mm} \times 1 \mathrm{~mm}$, respectively.

\section{CIRCUIT MEASUREMENT}

The mixers were measured via on wafer probing. The conversion loss and LO-to-IF, and LO-to-RF isolations were evaluated for each mixer. For all the three mixers, IF signal frequency is fixed at $2.5 \mathrm{GHz}$ and the RF and $\mathrm{LO}$ input power level are -10 and $10 \mathrm{dBm}$ respectively. For the sub-harmonic mixer, the conversion loss and isolation were plotted in Fig. 3(a). The conversion loss is about 10-12 dB and the LO-to-RF and LO-to-IF isolations are greater than $25 \mathrm{~dB}$. Since this SHP utilizes second harmonic of LO (LOx2), the LOx2-to$\mathrm{RF}$ and LOx2-to-IF isolations are more meaningful to investigate. The measured LOx2-RF and LOx2-IF isolations are both greater than $50 \mathrm{~dB}$. For the SB mixer with $180^{\circ}$ coupler, the conversion loss and LO-to-RF isolation were about 8-10 dB and $20 \mathrm{~dB}$, as shown in Fig. 3(b). For the SB mixer with $90^{\circ}$ coupler, the conversion loss and LO-to-RF were about 6-8 $\mathrm{dB}$ and $10 \mathrm{~dB}$, as shown in Fig. 3(c).

Table 1 summarized the performance of the three different mixers together with some recently published diode SHP mixers [3],[7]. Apparently the SHP mixer outmatches the SB mixer approach in LO-to-RF isolations, and chip size. The SB mixer with $180^{\circ}$ coupler has a higher conversion loss compared with the one with $90^{\circ}$ coupler, with a better LO-to-RF isolation but worse return loss, smaller bandwith, and a larger size. Compared with previously reported diode SHP mixer results [3], the SHP mixer in this paper has a better conversion loss, wider bandwidth, and comparable isolation with a larger area than the unit mixer in [3]. The conversion loss in [7] is a little better with a lower LO drive power due to the freedom of hybrid approach to select proper mixing diode elements.

\section{SUMMARY}

Three circuit topologies are evaluated for MMIC broadband diode mixers at $16.5-33 \mathrm{GHz}$. The mixers are manufactured using commercial available MMIC foundry process and achieve rival performance compared with previously reported results. Since the three MMIC mixer chips are fabricated on a common GaAs substrate, the topology evaluation can be perform on a fair basis. Measurement results show that the SHP mixer outmatches the SB mixers. 


\section{ACKNOWLEDGEMENT}

This work is supported by National Science Coucil of Taiwan, ROC (Contract No. NSC88-2219-E-002-015). The authors would like to thank for the Chip Implementation Center of Taiwan for the foundry service coordinate effort. Thanks also go to Dr. G. W. Huang of National Nano Device Labortory of Taiwan for the help of the testing effort.

\section{REFERENCES}

[1] S. A. Maas, Microwave Mixers, 2nd Edition, Artech House, Norwood, MA, 1992.

[2] Philips Microwave D02AH V2.0 Design Manual, Phlips Microwave Lemeil, Jan., 1997.

[3] H. Okazaki and Y. Yamaguchi, "Wide-band SSB subharmonically pumped mixer MMIC," 1997 International IEEE/MTT-S Symposium Digest, vol. 2, pp. 1035-1038, June, 1997.

[4] K. W. Chang, T. H. Chen, H. Wang and S. A. Maas, "Frequency upconversion behavior of singly balanced diode mixers," 1991 International IEEE/AP-S Symposium Digest, vol. 1, pp. 222-225, London, Ontario, Canada, June, 1991.

[5] D. M. Posar, Microwave Engineering, ch. 11, 2nd Edition, Addision Wesley, 1998.

[6] H. Wang, Y. Hwang, L. Shaw, M. Ahmadi, M. Siddiqui, B. Nelson, D. Tait, B. Martin, R. Kasody, W. Jones, D. Brunone, and M. Sholley, "Monolithic V-band frequency converter chip set development using $0.2 \mu \mathrm{m} \mathrm{AlGaAs/InGaAs/GaAs} \mathrm{pseudomorphic} \mathrm{HEMT} \mathrm{technology,"} \mathrm{IEEE}$ Trans. on Microwave Theory and Tech., vol. 42, no. 1, pp. 11-17, Jan., 1994.

[7] A. Madjar, "A novel general approach for the optimum design of microwave and millimeter wave subharmonic mixers," IEEE Trans. on Microwave Theory and Tech., vol. 44, no. 11, pp. 19972000, Nov., 1997.

\section{Figure Captions}

Fig. 1. The (a) circuit schematic diagram and, (b) chip photo, chip size is $1.3 \times 1.1 \mathrm{~mm}^{2}$ of the MMIC SHP diode mixer..

Fig. 2. (a) The block diagram of a SB diode mixer. The chip photo of (b) the SB mixer with modified rat-race coupler, chip size is $2.1 \times 2 \mathrm{~mm}^{2}$, (c) SB mixer with Lange coupler, chip size is $1.5 \mathrm{x}$ $1 \mathrm{~mm}^{2}$.

Fig. 3 Measured conversion loss and isolation versus LO frequency of the three mixers: (a) SHP mixer, (b) SB mixer with $180^{\circ}$ coupler, and (c) SB mixer with $90^{\circ}$ coupler. IF frequency is fixed at $2.5 \mathrm{GHz}$ and $\mathrm{RF}$ and $\mathrm{LO}$ input power level are -10 and $10 \mathrm{dBm}$ respectively for down conversion.

Tabe 1

Summary of the features for the three MMIC broadband mixers and previously reported SHP mixers.

\begin{tabular}{|c|c|c|c|c|c|c|c|}
\hline $\begin{array}{c}\text { Mixer } \\
\text { Topology }\end{array}$ & Features & $\begin{array}{c}\text { Chip size } \\
\left(\mathrm{mm}^{2}\right)\end{array}$ & $\begin{array}{c}\text { RF Freq. } \\
(\mathrm{GHz})\end{array}$ & $\begin{array}{c}\text { Conversion } \\
\text { Loss }(\mathrm{dB})\end{array}$ & \begin{tabular}{|c|}
$\begin{array}{c}\text { LO power } \\
(\mathrm{dBm})\end{array}$ \\
\end{tabular} & $\begin{array}{l}\text { Isolation } \\
(\mathrm{dB})\end{array}$ & Ref \\
\hline $\begin{array}{l}\text { SHP } \\
\text { mixer }\end{array}$ & $\begin{array}{c}\text { MMIC, CPW, } \\
\text { gate HEMT diode }\end{array}$ & $0.9 \times 0.6$ & 21.6-31 & $13-15$ & 11 & & [3] \\
\hline $\begin{array}{l}\text { SHP } \\
\text { mixer }\end{array}$ & $\begin{array}{c}\text { Hybrid approach, } \\
\text { commercial mixing } \\
\text { diodes }\end{array}$ & & $25.5-31.5$ & $8-12$ & 5 & & [7] \\
\hline $\begin{array}{l}\text { SHP } \\
\text { mixer }\end{array}$ & $\begin{array}{l}\text { MMIC microstrip, } \\
\text { gate HEMT diodes }\end{array}$ & $1.3 \times 1.1$ & $16.5-33$ & $10-12$ & 10 & $\begin{array}{c}\text { LO-RF, LO-IF } \\
>25 \mathrm{~dB} \\
\text { LOx2-RF, LOx2-IF } \\
>50 \mathrm{~dB}\end{array}$ & $\begin{array}{l}\text { This } \\
\text { work }\end{array}$ \\
\hline $\begin{array}{l}180^{\circ} \mathrm{SB} \\
\text { mixer }\end{array}$ & $\begin{array}{l}\text { MMIC microstrip, } \\
\text { modified ratrace }\end{array}$ & $2.1 \times 2.0$ & $20.5-25.5$ & $8-12$ & 10 & $\begin{array}{c}\text { LO-RF, LO-IF } \\
>15 \mathrm{~dB}\end{array}$ & $\begin{array}{l}\text { This } \\
\text { work }\end{array}$ \\
\hline $\begin{array}{l}90^{\circ} \mathrm{SB} \\
\text { mixer }\end{array}$ & $\begin{array}{l}\text { MMIC microstrip, } \\
\text { Lange coupler }\end{array}$ & $1.0 \times 1.5$ & $20-31$ & $6-8$ & 10 & $\begin{array}{l}\text { LO-RF, LO-IF } \\
>10 \mathrm{~dB}\end{array}$ & $\begin{array}{l}\text { This } \\
\text { work }\end{array}$ \\
\hline
\end{tabular}




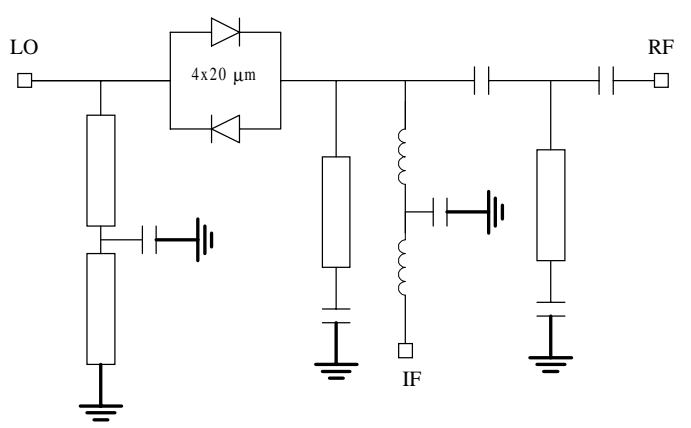

Fig. 1. (a)

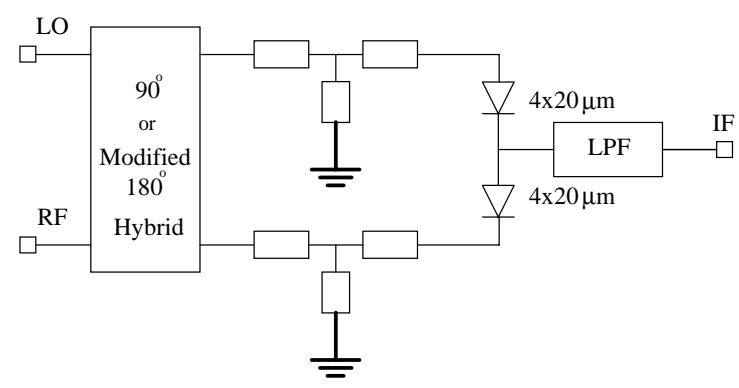

Fig. 2. (a)

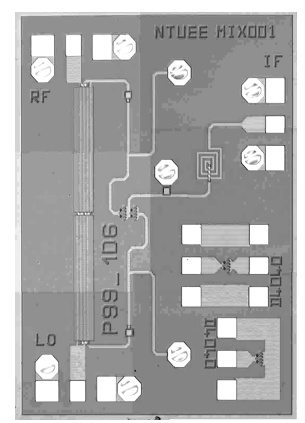

Fig. 2. (c)

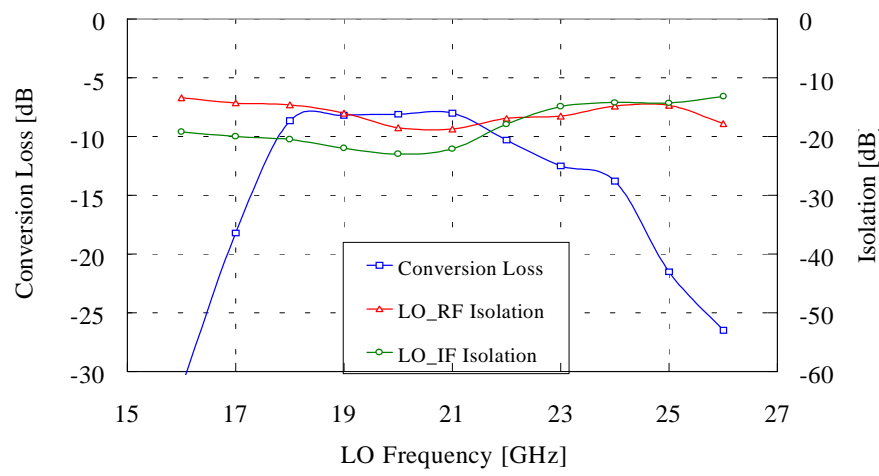

Fig. 3. (b)

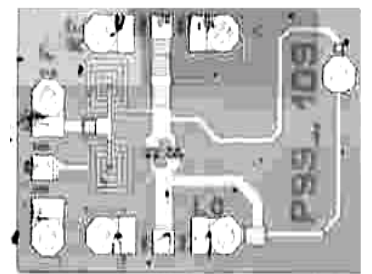

Fig. 1. (b)

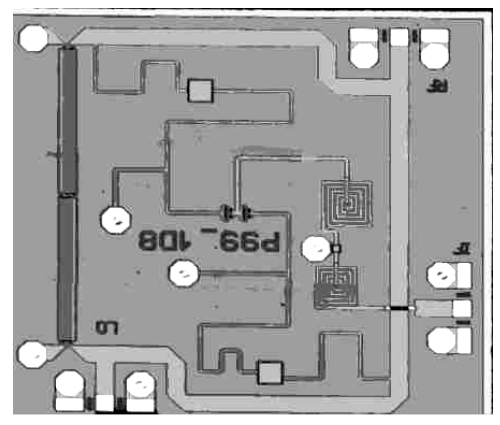

Fig. 2. (b)

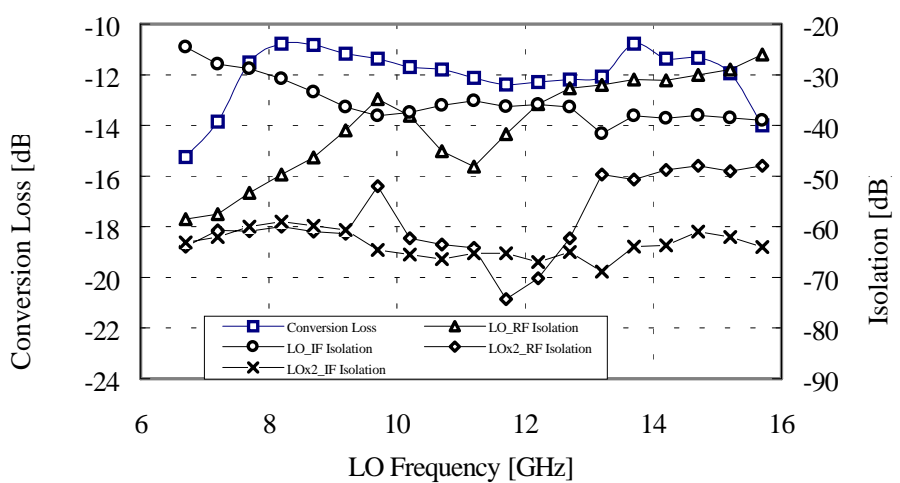

Fig. 3. (a)

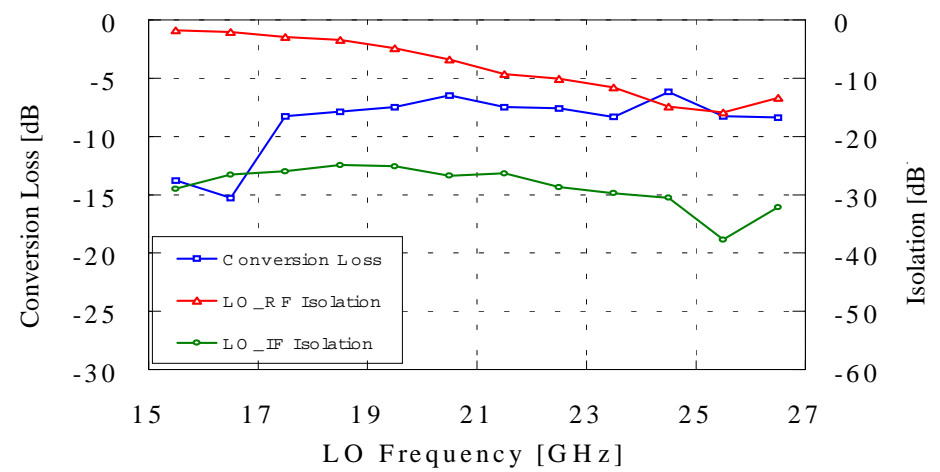

Fig. 3. (c) 